J. Egypt. Soc. Parasitol. (JESP), 50(3), 2020: 494-503

(Online: 2090-2549)

\title{
PERI-CYSTECTOMY VERSUS- CYSTOTOMY AND ENUCLEATION OF GERMINAL LAYER BY TISSUE SPEARING TECHNIQUE FOR LUNG HYDATID IN EGYPT
}

By

\author{
YASSER AHMED EL-SAYED ${ }^{1}$, EISSA ABDEL HAMED IBRAHIM ${ }^{2}$ \\ AND TOSSON ALY MORSY ${ }^{3}$
}

Consultant of Thoracic Surgery ${ }^{1}$ and Consultant of General Surgery ${ }^{2}$, Military Medical Academy ${ }^{1,2}$, Cairo, 11291, and Department of Parasitology, Faculty of Medicine, Ain Shams University ${ }^{3}$, Cairo, 11566, Egypt

(Correspondence: yasser.elsaide31@yahoo.com; eissa.abdelhameed@gmail.com;

Eissa-1961@yahoo.com \& morsyegypt2014@gmail.com)

\section{Abstract}

Echinococcal disease is caused by infection with the metacestode stage of the tapeworm Echinococcus, which belongs to the family Taeniidae. Four species of Echinococcus produce infection in humans; $E$. granulosus and E. multilocularis are the commonest, causing cystic echinococcosis (CE) and alveolar echinococcosis (AE), respectively. The clinical features of infection due to E. granulosus and E. multilocularis differed from each other. The two other species, E. vogeli and E. oligarthrus, cause polycystic echinococcosis but have only rarely had been ass-ociated with man. Surgery is still the gold standard treatment, chemotherapy is retracted to some patient, because yields inconsistent result. The study was carried out up on 16 male patients with single giant uncomplicated lung hydatid admitted to Kobry El Kobba Military Campus. The patients was randomly divided into two groups, GI included 8 patients, of whom 6 patients with right lung lesion and 2 with left lung lesion. One of the 6 patients with right side liver lesion was treated by cystotomy, after aspiration of cyst fluid and enucleation of germinal layer and de-roofing the cyst. G II included 8 patients, 4 patients with left side lesion and 4 with right side lesion and 2 patients had both lung and liver cysts. This group was pericystectomy treated by removal of entire cyst "endo cyst and peri-cyst". The most diagnostic tool was chest radiography and CT. Treatment included medical and surgical treatment was divided into conservative surgery and radical surgery. Both groups were treated by conservative surgical method but the outcome in GI was better than in GII.

Key words: Patients Hydatidosis, Pulmonary, Hepatic and Thoraco-hepatic, Surgical treatment.

\section{Introduction}

Pulmonary involvement with E. granulosus can lead to a variety of symptoms, including chronic cough (sometimes with accompanying hemoptysis or evacuation of cyst material), chest pain, pleuritis or dyspnea. Rupture of a cyst into a bronchus may lead to hemoptysis, respiratory distress, and asthma-like symptoms (Vijayan, 2007). If cysts rupture into the pleural space, a pleural effusion or empyema may develop (Bhatia, 1997). Lung abscesses can also occur. Approximately $60 \%$ of pulmonary hydatid disease affected the right lung and 50 to $60 \%$ involved the lower lobes and multiple cysts were common and approximately $20 \%$ of patients with lung cysts also have liver cysts (Baden and Elliott, 2003). Hydatidosis of organs outside of liver or lung were unusual as heart, kidney, bone \& ocular (Gogus et al, 2003) CNS (Mazyad et al, 1998) or pancreas (Akbulut et al, 2014) but can lead to significant morbidity and mortality (Gelman et al, 2000). Asymptomatic hydatidosis patients were usually diagnosed by radiological studies performed for other indications (Kjossev and Teodosiev, 2013). However, a smaller proportion of patients may become symptomatic after the complications, such as secondary infections, anaphylaxis, adjacent organ compression, and rupture (Daldou, 2015). Secondary cyst infections occurring as a result of cystobiliary communication are the most common risk factor for an increased intracystic pressure, erosion of adjacent structures by an enlarged cyst, and development of complicat ions (Mandolkar et al, 2015). Fever and acute hypersensitivity reactions including anaphylaxis may be the principal manifestation of cyst rupture. Hypersensitivity reactions were 
related to the release of antigenic material and secondary immunologic reactions. Agespecific prevalence of liver and pulmonary hydatid cysts increased with ages, indicating that infections continue to occur throughout patient life (Jenkins et al, 2005).

This study aimed to present the surgical techniques using in treatment of 16 hydatidosis male patients admited to Kobry- El-Kob ba Military Medical Campus.

\section{Material and Methods}

All the patients were male aged between 15 years and 50 years with average of 30 years. The 16 patients had 19 hydatid cysts distrib uted as ten patients with 10 right lung cysts with two patients each with additional left lobe liver cyst and six with left lung cysts with one patient with additional right lobe liver cyst on $7^{\text {th }}$ segment.

Clinical presentation: A symptomatic patient mainly with small liver cyst. Symptomatic lung patients were presented with a variety of symptoms, as chronic cough (sometimes with accompanied with hemoptysis or evacuation of cyst material), chest pain, pleuritis or dyspnea, with more than one sign and symptoms in same patient mainly with lung infection (Tab. 1).

Table 1: Clinical presentation of patients

\begin{tabular}{|l|l|}
\hline Symptom and sign & Number of patients \\
\hline A symptomtic & 3 patients \\
\hline Pain & 4 patients \\
\hline Cough & 2 patients \\
\hline Pain and cough & 2 patients \\
\hline Hempotesis & 1 patient \\
\hline Hydatoptysis & No \\
\hline Weight loss & 2 patients \\
\hline Chet and abdominal pain & 2 patients \\
\hline Dysnea & 4 patients \\
\hline Fever & 6 patients \\
\hline Allergy & 2 patients \\
\hline
\end{tabular}

All the patients were from the rural area dealing with farm animals and dogs. The diagnosis was established by history "clinical examination" and radiological examination "chest, x.ray, C.T chest and US" US abdomine showed liver leasion, CT abdominal and chest done. An immunologic test complement fixation test and indirect haemoagglutinoation were not used.

CT chest showed cystic lesion on the base of right lung (Fig. 1) CT chest and abdomen showedleft lung cyst and right hepatic cyst (Fig. 2).

Laboratory examinations: all patients were examined for $\mathrm{CBC}$, coagulation profile, liver function tests, renal function tests, and blood sugar. Also, ECG and respiratory function test were done.

Ethical considerations: All hydatidosis patients were informed about their surgical cases, and operation was done after obtaining written consent from them and investigation done to all patients.

The patients were randomly divided into two groups. GI included 8 patients of whom six with right lung lesions and two with left lung lesions. One patient of these six patients had right side liver lesion, which was treated by conservative surgical methods such as cystotomy after aspiration of cyst fluid and enucluation of germinal layer and de-roofing the cycle without capitonnage and insertion of chest tube. GII included 8 patients with cystic lung lesions. Four patients were four with left side lesions and four with right side lesions, of whom two patients had left liver as well. This group was treated by peri-cystectomy "removal of entire cyst i.e. peri-cyst and endocyts" part of lung tissue was removed during peri-cystectomy. Patients with bilateral disease were managed with staged thoractomies after an interval 4 to 6 months minimally after 6 weeks liver hydatid post pone 6 month after treatment of lung hydatid to minimize surgical trauma to patient.

Surgical technique: Operation was done to all patients (GI \& GII) under general endotrachial anesthesia. The patients in the lateral 
decubitus position, the skin is prepared by painting with skin antiseptic "povidone-lodine" and draping patient. Posterolateral thoractomy through the fifth intercostal space was accomplished (Fig. 3 A\& B). Patients in GI $\&$ GII were given (Fig. 14).

The thoractomy wound and operating area a part from the area contained cyst, were cavered by sponges moistened by hypertonic saline to prevent inadvertent implantation of scoleces in the wound or operative area.

Patients GI: 1- Exploration site of cyst and mobilization of cyst (Fig. 4 A\& B), 2- Insertion of metallic needle (Fig. 5 A\& B), 3Aspiration of all cystic fluid by suction (Fig. 6), 4- Injection of scolocidal agent via canula (Fig. 7), 5- Reaspiration of injected scolicidal agent again (Fig. 8), 6- Needle site was enlarged by cutting cystic wall by an electrocautery. Germinate membrane was easily taken out (Fig. 9A \& B), 7- After removal of germinal layer, rsidual cavity was carefully examine and irrigated by saline and shack for air-leak from bronchial cavities leak-was closed by a $3 / 0$ coated vicryl (Fig. 10A \& B), 8- Part of cystic wall removed "cystotomy" and left opened and insertion of 2- chest tu-be one at lung base and second at apex (Fig. 11 A \& B), and 9- Wound closure in layer aft- er good haemostasis, intercostal nerve block, good lung inflation, and ICU patient nursed (Fig. 12A \& B, Fig. 13A \& B).

Patients GII: 1 - The procedure done as in GI until approach to cystic lesion (Fig. 16A
\& B) were peri-cystectomy done, 2- The cyst was usually seen as a soft swelling on the pulmonary parenchyma surface, 3- Any bleeding point "blood vessel" and large bronchial were ligated by $3 / 0$ coted vacrel (Fig. 17 A\& B), 4- Peri-cystectomy done and open peri-cyst to showing germinal layer and lung tissue surrounding it and send for histopathological examination (Fig. 18 A\& B), 5- Suturing raw area of lung parenchyma after good haemostasis (Fig. 19), 6- inseration of 2 chest tube one at base of lung and other at apex of lung (Fig. 20), 7-Closure of wound in layer (Fig. 21 A\& B, Fig. 22 A\& B), and 8Good inflation of lung, intercostal nerve block and nursing patient in ICU.

Postoperative: $1-\mathrm{O}_{2}$ saturation monitoring, 2- Plain X-ray chest on $2^{\text {nd }}$ post-operative day, 3- Chest phasiotherapy, 4- Monitoring chest tube and removed after good lung inflation, 5- Removal of suture after 10-15 days, 6-Antibiotic, preoperative and post-operative for 3 days, and 7- Mebendazol 10mg $/ \mathrm{kg} /$ day 2 days before operation and 1 week postoperative. Procedure was repeated 3 times by hypertonic saline injection in cystic cavity, left 15-20 minute and then de-roofing cysts.

\section{Results}

The predominant complains of all patients were chest pain followed by cough. The predominant signs were fever then dyspnea and allergy, but without hydatoptysis i.e. no cystbronchial communication in the patients.

Table 2: Distribution of patients by type of operation

\begin{tabular}{|l|l|c|}
\hline Patients & Type of operation & Number \\
\hline GI & Pericystectomy & 8 patients \\
\hline GII & Cystotomy and enucluation of germinal layer & 8 patients \\
\hline
\end{tabular}

Comparison between GI \& GII: as to hospi- wound infection, air leakage, bronchiopleural tal stay, ventilation, haemorrhage, empyema, fistula, and respiratory failure (Tab. 3).

Table 3: Comparison of postoperative complication between GI and GII

\begin{tabular}{|l|l|l|}
\hline Postoperative & \multicolumn{1}{|c|}{ GI } & \multicolumn{1}{|c|}{ GII } \\
\hline Hospital stay & From 5-8 days & 10 days up to 15 days \\
\hline Ventilation off & $\begin{array}{l}\text { 4 cases not ventilated \& 4 ventilated off 3 } \\
\text { days (postoperative) }\end{array}$ & $\begin{array}{l}\text { 3 case not ventilated, 3 case ventilated and off ventilation sec- } \\
\text { ond days postoperative in 1 case \& 2 cases ventilated 5 days } \\
\text { postoperative }\end{array}$ \\
\hline Hemorrhage & $\begin{array}{l}\text { 2cases mild hemorrhage not need blood } \\
\text { transfusion }\end{array}$ & $\begin{array}{l}\text { mild hemorrhage and on severe open and blood transfusion } \\
\text { done }\end{array}$ \\
\hline Empyema & No & 1 case \\
\hline Wound infection & One case mild wound infection & $\begin{array}{l}\text { case; One mild wound infection, One severe wound infection } \\
\text { and pus come out }\end{array}$ \\
\hline
\end{tabular}


Table 4: Comparison of outcome after 6 month of follow up between GI cystotomy \& GII pericystectomy for 16 patients

\begin{tabular}{|l|l|l|}
\hline Postoperative complication & \multicolumn{1}{|c|}{ GI } & \multicolumn{1}{|c|}{ GII } \\
\hline Pain & $\begin{array}{l}\text { Mild chest pain at incision } \\
\text { site in 2 patient }\end{array}$ & $\begin{array}{l}\text { Mild chest pain at incision site treated by dechlofnic, and } \\
\text { one severe treated by repeated intercostal nerve block }\end{array}$ \\
\hline Cough & No & 2 patient i.e., bronchial asthma and other chest infection \\
\hline Hemptosis & No & No \\
\hline Recurrence & No & No \\
\hline Dyspnea & No & Dyspnea in 3 patient \\
\hline $\begin{array}{l}\text { Wound complication and } \\
\text { fistula }\end{array}$ & $\begin{array}{l}\text { 2 patient showing hypertonic } \\
\text { scar at site of operation }\end{array}$ & $\begin{array}{l}\text { 3 patients, 2 infected granuloma and 1 showed fistula at } \\
\text { incision site treat conservative }\end{array}$ \\
\hline
\end{tabular}

No death at all, pre-or postoperative patients were followed for 6 months, although continuning follow up was attempted through our hospital in out patient's clinic.

The most common complication in the early postoperative wound infection (Tab. 4) in severe form of infection, the patient were treated successfully by open suture line, daily dressing and a 10 days course of antibiotic. One patient, who had developed mild bronchiectatic change 6 month after operation in GII and treated conservative did'nt need lobectomy nor segmendectomy. Complications were in GII more than GI, as in GII there was extensive surgery (pre-cystectomy i.e. ner to lobectomy or segmentectomy) than in GI cystotomy i.e. fanstration of cyst. The severe complications were low in GI \& GII, because all patients presented with uncomplicated isolated lung cysts. There was neither respiratory failure nor air leakage in the patients.

\section{Discussion}

Human echinococcosis is a parasitic disease caused by tapeworms of the genus Echinococcus. The two most important forms in humans are cystic echinococcosis; hepatic hydatidosis and alveolar hydatidosis. Humans are infected through ingestion of parasite eggs in contaminated food, water or soil, or after direct contact with animal reversoir hosts. Echinococcosis is always expensive and complicated to treat and may require extensive surgery and/or prolonged drug therapy (WHO, 2019). Generally, hepatic alveolar and cystic echinococcosis was both lifethreatening diseases because of their medical and economical impact and their wide geographical distribution (Rausch and D'Alesandro, 2002). Prevention of cystic echinococcosis is best achieved by avoiding close con- tact with dogs (Sabry et al, 2012). Careful washing of vegetables and contaminated fresh produce can also reduce infection. Prohibition of home-slaughter of sheep prevénte dogs from consuming infected viscera, thus to cut the zoonotic life cycle sheep-dog-man (Haridy et al, 2000).

Previously, open surgery was the only option for the treatment of echinococcal cysts. However, experience was grown with other potential treatment modalities, including, laparoscopic techniques, the PAIR procedure (Ibrahim and Morsy, 2020) and chemotherapy, which in certain cases, rendered open techniques unnecessary (Dervenis et al, 2005).

But, a problem with medical therapy is that the drugs do not penetrate the tissue barriers to reach inner compartments of the metacestode very successfully. Poor correlation between intracystal concentrations of albendazole and the viability of scolices has been reported (Manterola et al, 2005), and efficacy may correlate more with duration of therapy than with the serum or cyst levels achieved (GilGrande et al, 1993). However, therapeutic treatment for alveolar echinococcosis generally was less effective than for the other cystic fo-rm, in part because delayed in diagnosis often render many lesions inoperable. Screening high risk populations to detect alveolar hydatid disease earlier might improve the prognosis (Kadry et al, 2005). Animal experiments, term chemotherapy inhibited metacestode proliferation, at least partially destroyed the germinal layer and protoscolices, suppressed metastases and prevented calcification, but metacestodes were not killed (Ammann et al, 1998). The optimal duration of therapy and whether or not prolonged or lifelong therapy is indicated remains unclear. 
Therapy often is administered for as long as 10 years or more, and monitoring of blood levels to avoid toxic levels is recommended (Ammann and Eckert, 1996). Despite apparent success of chemotherapy in the majority of patients, late cholestatic complications or variceal bleeding occurred in approximately $30 \%$ of patients with hilar fibrosis, and that noncurative resection combined with albendazole gave a 15 year survival rate of $87 \%$ (Stettler et al, 2003).

In most cases of hydatid liver disease, treatment consisted of medical therapy with albendazole, in combination with either surgery or the PAIR procedure. The most appropriate treatment of hepatic cyst varied with patient characteristics as age, co-morbidities, individual preference, cyst characteristics as number, size, locations, presence of complications, and physician as experience and resources (Rinaldi et al, 2014).

Surgery is generally the preferred option for large liver cysts (diameter $>10 \mathrm{~cm}$, especially if associated with multiple daughter cysts), superficially located single liver cysts which have a risk of rupture, complicated cysts such as those accompanied by infection, compression or obstruction, or cysts in lung, kidney, bone, brain or other organs (Safioleas et al, 2006). However, many authors reported that urgery is the mainstay of treatment for hydatidosis, once surgery was pursued; results are satisfactory (Aeberhard et al, 1996; Georgiou et al, 2015; Marom et al, 2019), especially in pulmonary ones (Vaccarezza and Tricerri, 1951; Xanthakis et al, 1972; Buttenschoen et al, 2003)

In the present patients, conservative surgical technique i.e. cystotomy without obletration of cystic cavity and pericystectomy were the method of choice for all the patients with cysts peripherally located and moderate in size. So, in the present technique cystotomy (fansteration) of pulmonary cyst and pericystectomy were the conservative procedure to conserve lung physiology.

In the present study, the vacuation of cyst contant "hydatid fluid-scolesis" was done to prevent implantation of scolosis and anphelactic shock-removal of germinal layer to prevent growth of cyst and management of cyst cavity.

Contraindications WHO recommended that surgery was contraindicated in: patients with very poor general condition, patients at the extremes of age, pregnant women, patients with multiple cysts or cysts that were difficult to access and patients with dead or totally calcified cysts

In the present patients, mebendazole 10mg/ $\mathrm{kg} /$ day 2 days was given before operation and a week postoperative to prevent implantation of sclosis and recurrent of disease. However chemotherapy treatment was disappointed in four patients and surgery were still the most effective therapy and required urgent surgery for massive haemoptysis, cyst ruptured into the bronchus or pleural cavity. Surgery must remain the primary treatment for most patients with pulmonary hydatid disease. Adjunctive chemotherapy before and after surgery reduced the risk of recurrence by inactivating protoscolices and lessening the tension of the cysts for easier cyst removal (Erzurumlu et al, 2000). If spillage of cyst contents occurred, either spontaneously or following iatrogenic manipulation, it was recommended that either mebendazole or albendazole be given to reduce the risk of secondary hydatidosis. But, the optimal duration of chemotherapy before and after surgical procedures was not determined. WHO (1996) recommended that therapy should be begun at least four days before surgery and be continued for at least one month (albendazole) or three months (mebendazole) following surgery.

Generally speaking, man is infected hydatid disease by the ingestion of eggs mixed with uncooked vegetables, fruits, and drinking water, or by handling the soil and dirt or by direct contact with animal hair containing eggs. Gastric and enteric digestion of eggs facilitated the release of embryos. Embryos subsequently attach to the duodenal or jejunal wall by their hooklets and penetrate the intestinal wall to the liver via the portal cir- 
culation. Most of the embryos stucked in the liver sinusoids but smallest embryos with diameters $<0.3 \mathrm{~mm}$ may pass through the hepatic sinusoids and, hepatic vein and inferior vena cava (IVC) to enter the right heart and settle in the lungs (Aletras and Symbas, 2000). Also, embryos can reach the lungs via the thoracic duct via lymphatics of the small intestine and via an internal jugular vein, and right side of the heart to the lungs, or they bypassed the liver and involved the lungs (Halezeroglu et al, 2012) or via lymphatics of the dome of the liver and diaphragm and ascended to the parasternal and intercostal lymph nodes or via the liver venal-venous anastomosis and the Retzius space (Isitmangil et al, 2003). A most dangerous mode of infection was direct pulmonary exposure through the inhalation of air contaminated with Echinococcus eggs; that is why lung infection is common in sheep rearing rural areas Borrie et al. has shown that eggs administered to sheep via a tracheostomy resulted in the development of lung cysts (Borrie et al, 1965). The embryo gradually transformed into a hydatid cyst. Lungs may also become the site of secondary hydatidosis due to the rupture of a primary cyst resulting in dissemination of multiple daughter cysts and scolices, within the lung parenchyma, an adventitial layer of the primary cyst, intrabronchial, or metastatic (Ramos et al, 2001). Metastatic lung lesions develop due to rupture of the cyst into right heart chamber (Odev et al, 2002), IVC (Röthlin, 1998) or rupture of a bone cyst (Mazyad et $a l, 1999)$. The superficial large was likely to rupture, infected cysts, cysts in vital anatomical locations, and cysts exerting substantial mass effect indicated surgery (McManus et al, 2003).

Now why surgical intervention? the goal to removal of the entire cyst and safing lung parenchyma as much as possible and without allowing intraoperative spillage. Various surgical techniques available include enucleation, pericystectomy, cystostomy with capitonnage, open aspiration, and lung re- section (Nabi and Waseem, 2010). Prevention of intraoperative spillage can be achieved by placing gauze soaked with a hypertonic saline solution $(20 \%)$ or povidone-iodine solution (Koul et al, 2010).

Any now what is enucleation of germinal layer? Enucleation consists of removal of the cyst with its intact germinative membrane. It is suitable for the small pulmonary hydatid cysts $<5 \mathrm{~cm}$ in diameter with little risk of rupture. Removal of the cyst was aided by the intrabronchial positive pressure ventilation. Larger cysts should not be treated with this method to avoid the risk of rupture (Bilgin et al, 2004). With enucleation, pericyst remains as such; thus, there is a risk of postoperative air leak and infection. Pericystectomy involved removal of hydatid cyst along with its pericyst. The proponents of this method included that pericystic cavity may undergo amyloid degeneration, increased risk of airway leak and calcification (Perez-Fontana, 1949), and achieved complete removal of the parasite (Kontaxis, 1983).

\section{Conclusion}

Liver frequently produces no symptoms. Significant symptoms are unusual before the cyst reached at least $10 \mathrm{~cm}$ in diameter, but if become large, hepatomegaly with or without associated right upper quadrant pain, nausea and vomiting occurred. Pulmonary involvement with E. granulosus can lead to a variety of symptoms, including chronic cough, chest pain, pleuritis or dyspnea. Rupture of a cyst into a bronchus may lead to hemoptysis, respiratory distress, and asthma-like symptoms. If cysts rupture into the pleural space, a pleural effusion or empyema may develop. Lung abscesses can also occur.

Surgery treatment was choice for the pulmonary hydatidosis patients, conservative surgery; i.e. cystotomy or peri-cystectomy proved better than extensive surgery unless extensive surgery was not indicated. In GII obliteration of pericystic cavity was after pericystectomy to prevent bleeding and decrease infection incidence. In GI keep cyst open to help absorption of discharge fluid via lymphatic of pleural 
space and good results were in GI than in GII.

\section{Recommendations}

1-Surgery is the first treatment for pulmonary hydatid patients. 2-Staging surgery is choice for patient with bilateral pulmonary cyst or pulmonary and liver cysts. 3-Albendazole was used pre- $\&$ post-operative in dose $10 \mathrm{mg} /$ $\mathrm{kg} /$ day. 4- Conservative pulmonary surgery is choice for patients especially in endemic area. 5- Chest radiograph and CT is choice to diagnose pulmonary hydatid. 6- Hydatidosis is risk zoonotic disease and prevention is safe than treatment especially in endemic area.

\section{References}

Aeberhard, P, Fuhrimann, R, Strahm, P, Thommen, A, 1996: Surgical treatment of hydatid disease of the liver: An experience from outside the endemic area. Hepatogastroenterology 43, 9: 627-36.

Akbulut, S, Yavuz, R, Sogutcu, N, Kaya, B, Hatipoglu, S, et al, 2014: Hydatid cyst of the pancreas: Report of an undiagnosed case of pancreatic hydatid cyst and brief literature review. World J. Gastrointest. Surg. 6, 10:190-200

Aletras, H, Symbas, PN, 2000: Hydatid disease of the lung. In: General Thoracic Surgery, Shields, TW, LoCicero, J, Ponn, RB (eds.). Philadelphia: Lippincott Williams and Wilkins

Ammann, RW, Eckert, J, 1996: Cestodes: $E c$ hinococcus. Gastroenterol. Clin. North. Am. 25: 655-9.

Ammann, RW, Fleiner-Hoffmann, A, Grim, F, Eckert, J, 1998: Long-term mebendazole theapy may be parasitocidal in alveolar echinococcosis. J. Hepatol. 29:994-6.

Bhatia, G, 1997: Echinococcus. Semin. Respir. Infect. 12:171-5.

Bilgin, M, Oguzkaya, F, Akçali, Y, 2004: Is capitonnage unnecessary in the surgery of intact pulmonary hydatic cyst? ANZ J. Surg. 74:40-2.

Borrie, J, Gemmell, MA, Manktelow, BW, 1965: An experimental approach to evaluate the potential risk of hydatid disease from inhalation of Echinococcus ova. Br. J. Surg. 52:876-8.

Buttenschoen, $K$, Buttenschoen, $C$, Langenbecks, D, 2003: Echinococcus granulosus infection: The challenge of surgical treatment. Arch. Surg. 388, 4:218-30.

Daldou, S, 2015: Spontaneous cutaneous fistula of hydatid liver cysts (in French). Ann. Dermat- ol. Venereol. 142:736-41.

Dervenis, C, Delis, S, Avgerinos, C, et al, 2005: Changing concepts in the management of liver hydatid disease. J. Gastrointest. Surg. 9:869-74.

Erzurumlu, K, Hokelek, M, Gonlusen, L, et al, 2000: The effect of albendazole on the prevention of secondary hydatidosis. Hepatogastroenterology 47:247-52.

Gelman, R, Brook, G, Green, J, et al, 2000: Minimal change glomerulonephritis associated with hydatid disease. Clin Nephrol 2000; 53:152.

Georgiou, GK, Lianos, GD, Lazaros, A, Harisis, HV, Mangano, A, et al, 2015: Surgical management of hydatid liver disease. Int. J. Surg. 20:118-22.

Gil-Grande, LA, Rodriguez-Caabeiro, F, Prieto, JG, et al, 1993: Randomised controlled trial of efficacy of albendazole in intra-abdominal hydatid disease. Lancet 342:1269-71.

Gogus, C, Safak, M, Baltaci, S, Turkolmez, K, 2003: Isolated renal hydatidosis: Experience with 20 cases. J. Urol. 169:186.

Halezeroglu, S, Okur, E, Tanyü, MO, 2012: Surgical management for hydatid disease. Thorac. Surg. Clin. 22:375-85.

Haridy, FM, Ibrahim, BB, Morsy, TA, 2000: Sheep-dog-man: The risk zoonotic cycle in hydatidosis. J. Egypt. Soc. Parasitol. 30, 2:423-9.

Ibrahim, EA, Morsy, ATA, 2020: Liver hydatid in young age treated percutaneous by using puncture-aspiration-injection-reaspiration(PAIR) technique. J. Egypt. Soc. Parasitol. 50, 2: 431-8

Isitmangil, T, Toker, A, Sebit, S, Erdik, O, Tunc, H, et al, 2003: A novel terminology and dissemination theory for a subgroup of intrathoracic extrapulmonary hydatid cysts. Med. Hypotheses 61:68-71.

Jenkins, DJ, Romig, T, Thompson, RC, 2005: Emergence/re-emergence of Echinococcus spp.- a global update. Int. J. Parasitol. 35:1205-9.

Kadry, Z, Renner, EC, Bachmann, LM, et al, 2005: Evaluation of treatment and long-term follow-up in patients with hepatic alveolar echinococcosis. Br. J. Surg. 92:1110-6.

Kjossev, KT, Teodosiev, IL, 2013: Cutaneous fistula of liver echinococcal cyst previously misdiagnosed as fistulizated rib osteomyelitis. Trop. Parasitol. 3:161-5.

Kontaxis, AN, 1983: Surgical treatment of pulmonary hydatidosis. J. Thorac. Cardiovasc. Surrg. 85:799-800.

Koul, PA, Singh, AA, Ahanger, AG, Wahid, A, Sofi, BA, 2010: Optimal duration of preoper 
ative anti-helminthic therapy for pulmonary hydatid surgery. ANZ J. Surg. 80:354-7.

Mandolkar, SD, Ramakanth, B, Anil-Kumar, PL, et al, 2015: Cystocutaneous fistula of the le$\mathrm{ft}$ lobe of liver: an extremely rare presentation of hydatid liver cyst. Int. Surg. J. 2:109-11

Manterola, C, Mansilla, JA, Fonseca, F, 2005: Preoperative albendazole and scolices viability in patients with hepatic echinococcosis. World J. Surg. 29:750-6.

Marom, G, Khoury, T, Abu Gazla, S, Merhav , H, Padawer, D, et al, 2019: Operative treatment of hepatic hydatid cysts: A single center experience. Asian J. Surg. 42, 6:702-7.

Mazyad, MAM, Morsy, TA, Habib, KhSM, 1999: Vertebral unilocular hydatidosis in a shepherd and his wife. J. Egypt. Soc. Parasitol. 29, 2:547-50

Mazyad, MAM, Mostafa, MM, Morsy, TA, 1998: Spinal cord hydatid cysts in Egypt. J. Egypt. Soc. Parasitol. 28, 3:655-8.

McManus, DP, Zhang, W, Li, J, Bartley, PB, 2003: Echinococcosis. Lancet 362:1295-304.

Nabi, MS, Waseem, T, 2010: Pulmonary hydatid disease: What is the optimal surgical strategy? Int. J. Surg. 8:612-6.

Odev, K, Acikgözoglu, S, Gormüs, N, Aribas, OK, Kiresi, DA, et al, 2002: Pulmonary embolism due to cardiac hydatid disease: Imaging findings of unusual complication of hydatid cyst. Eur. Radiol. 12:627-33.

Perez-Fontana, V, 1949: Nuevo metodo de operar en el quiste hidatico del pulmon. Arch. Pediatr. Urug. 9:5-9.

Ramos, G, Orduña A, García-Yuste, M, 2001: Hydatid cyst of the lung: Diagnosis and treatment. World J. Surg. 25:46-57.

Rausch, R, D'Alesandro, A, 2002: The epidemiology of echinococcosis caused by Echinoco-

ccus oligarthrus and $E$ vogeli in the neotropics. In: Craig P, Pawlowksi Z, editors. Cestode zoonoses: echinococcosis and cysticercosis. Amsterdam: IOS Press.

Rinaldi, F, Brunetti, E, Neumayr, A, Maestri, M, Goblirsch, S, et al, 2014: Cystic echinococcosis of the liver: A primer for hepatologists. World J. Hepatol. 6, 5:293-305.

Röthlin, MA, 1998: Fatal intraoperative pulmonary embolism from a hepatic hydatid cyst. Am. J. Gastroenterol. 93:2606-7.

Sabry, AA, Morsy, ATA, Morsy, TA, 2012: Zo lonoses from dogs with special reference to Egypt. J. Egypt. Soc. Parasitol. 42, 3:583-604.

Safioleas, MC, Misiakos, EP, Kouvaraki, M, et al, 2006: Hydatid disease of the liver: a continuing surgical problem. Arch. Surg. 141:1101-8.

Stettler, M, Fink, R, Walker, M, et al, 2003: In vitro parasiticidal effect of nitazoxanide against Echinococcus multilocularis metacestodes. Antimicrob. Agen. Chemother. 47:467-70.

Vaccarezza, O, Tricerri, F, 1951: Results of the surgical treatment of pulmonary hydatid cyst; 41 cases treated by pulmonary resection without mortality. Prensa Med. Argentina 38:1079-82.

Vijayan, VK, 2007: How to diagnose and manage common parasitic pneumonias. Curr. Opin. Pulm. Med. 13:218.

WHO, 1996: Guidelines for treatment of cystic and alveolar echinococcosis in humans. Informal Working Group on Echinococcosis. Bull. WHO $74: 231$

WHO, 2019: Echinococcosis campaign in Eastern Europe, Geneva.

Xanthakis, D, Efthimiadis, M, Papadakis, G, et al, 1972: Hydatid disease of the chest: Report of 91 patients surgically treated. Thorax $27,5: 517-$ 28.

\section{Explanation of figures}

Fig. 1: Chest $\mathrm{CT}$ showed hydatid lung cyst

Fig. 2: CT chest and liver abdomen showed cystic lesion at base of left lung and cyst lesion right liver.

Fig. 3: A, B: Thoracotomy incision posterlateral incision in 5 intercostal space right lung lesion

Fig. 4: A,B: Expiration of site of lesion and localization of cysts.

Fig. 5: A,B: Insertion of metallic canula after localization of cysts.

Fig. 6: Aspiration of hydatid fluid by suction nasal.

Fig. 6: Injection of scolicidal agent

Fig. 7: Prepared metallic canula for respiration of injected hypertonic saline

Fig. 8: A,B: De-roofing the cyst wall, and take-out germinal layer.

Fig. 9: A,B: Examined cystic cavity and check cavity for air leak by felling cavity by saline and check for air bubble \& aspiration of fluid again.

Fig. 10: A,B: Leave cyst open and insertion 2- under water seal (chest tube)

Fig. 11: A,B: Closure of wound in layer after insertion of 2- chest tube one at apex of lung and other at base.

Fig. 12: A,B: Closure drosolumber fascia, subcutaneous and skin.

Fig. 13: Thoracotomy incision (left 5- intercostal space) posto-lateral incision.

Fig. 14: A,B: Exploration of chest (site of cysts) and dissection of cysts from surrounding tissue and localization of cysts.

Fig. 15: A,B: Dissection of cyst (pre-cyst)

Fig. 16: A, B: Any bleeding point and large bronchus must transfixed ligation. 
Fig. 17: A,B: Peri-cyst. A intact \& B open pericyst showed germinal layer and examined histopathological, with lung (healthy tissue arround). Fig. 18: Suturing raw area of lung after good haemostasis.

Fig. 19: Insertion of chest tube "under-water scale"

Fig. 20: A,B: Closure of wound in layer after insertion of chest tube.

Fig. 21: A,B: Closure of dorsal muscle and dorsal lumber fascia and subcutaneous and closure of skin subcutcular.
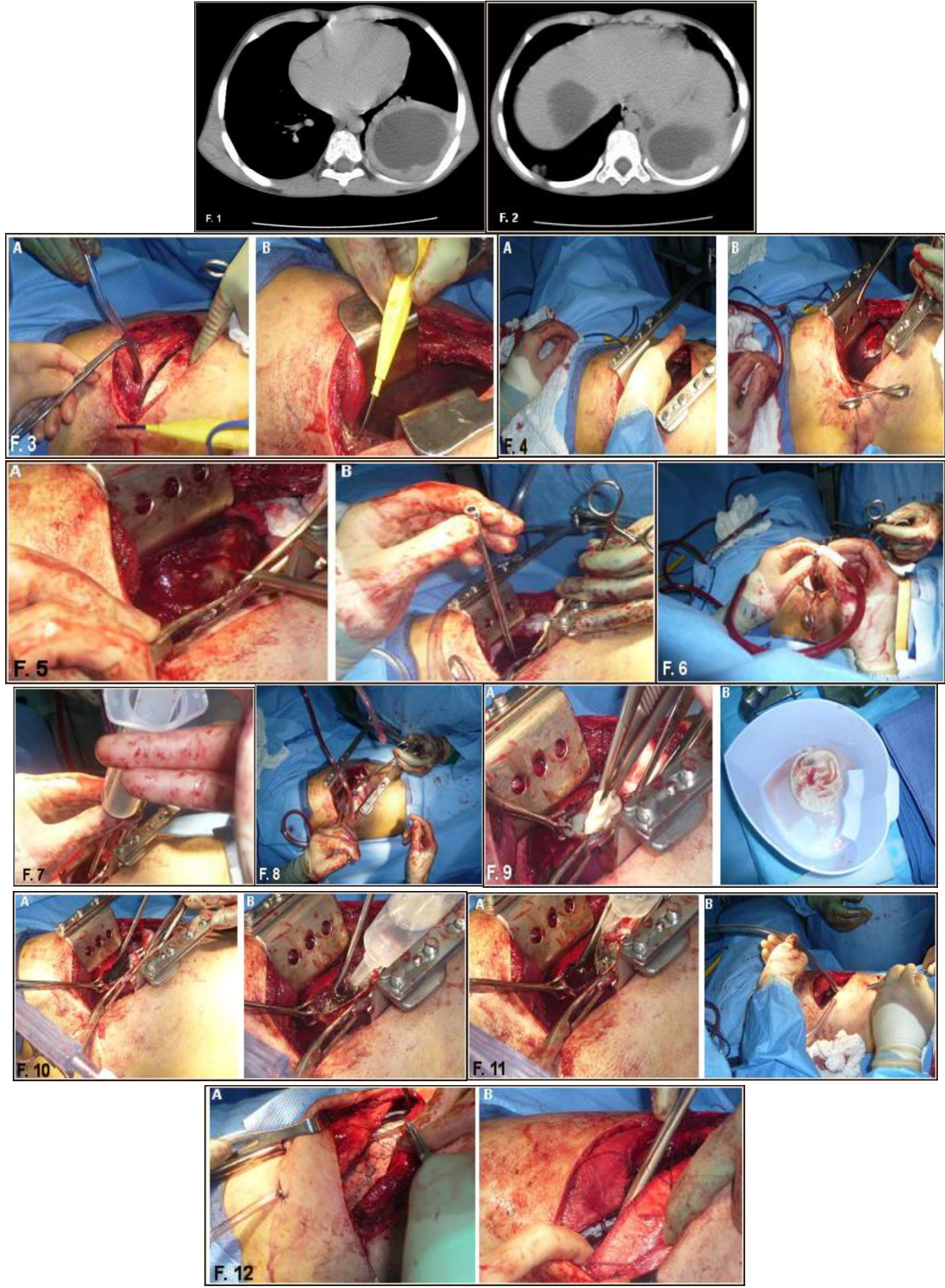

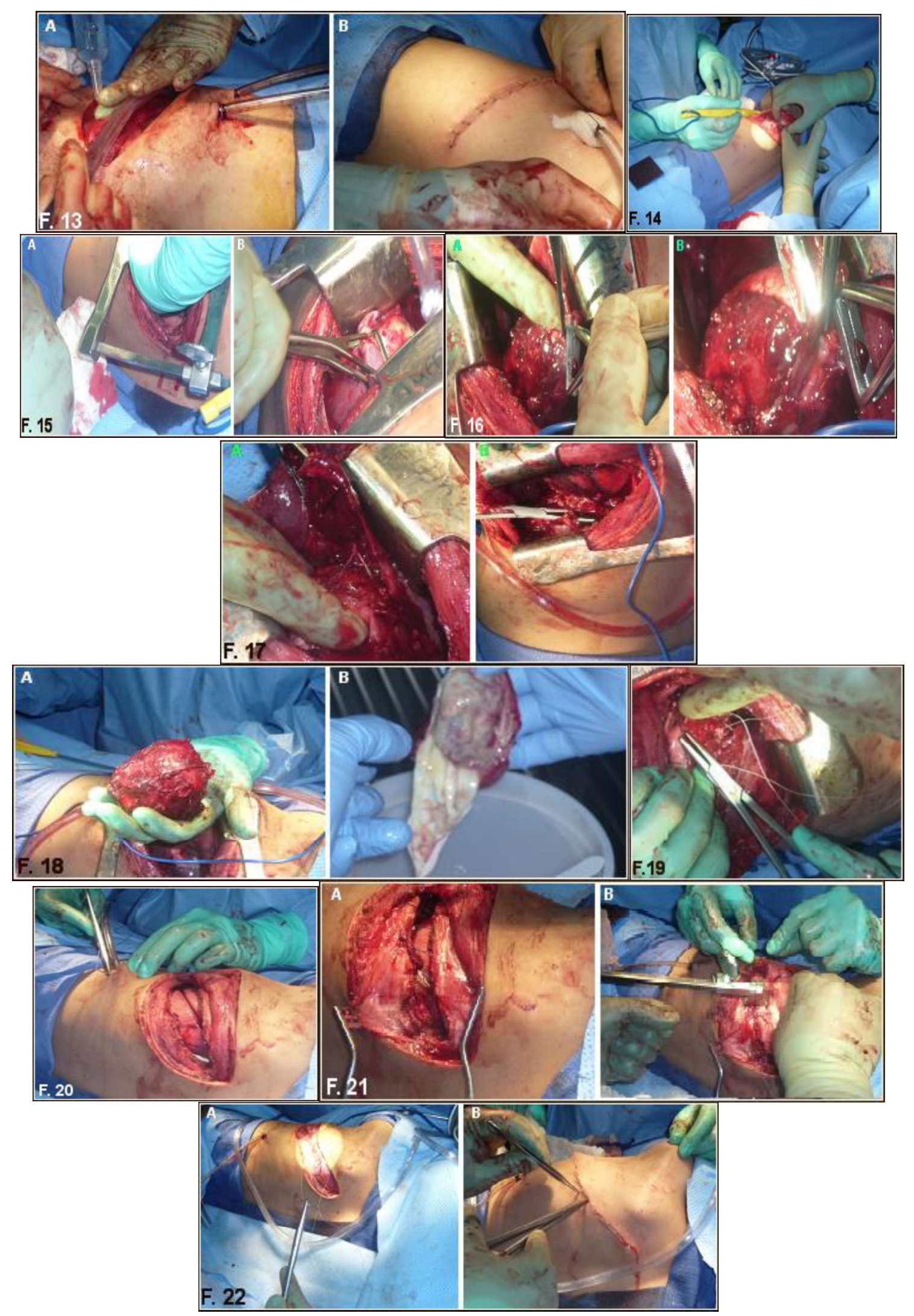